\title{
Cerebellar atrophy in a patient with velocardiofacial syndrome
}

David R Lynch, Donna M McDonald-McGinn, Elaine H Zackai, Beverly S Emanuel, Deborah A Driscoll, Linton A Whitaker, Kenneth H Fischbeck

\section{Department of Neurology, University of Pennsylvania School of Medicine, Philadelphia, PA, USA D R Lynch \\ K H Fischbeck \\ Department of Pharmacology, \\ University of \\ Pennsylvania School \\ of Medicine, \\ Philadelphia, PA, USA \\ D R Lynch}

Department of Pediatrics, University of Pennsylvania School of Medicine,

Philadelphia, PA, USA

D M McDonald-

McGinn

E H Zacka

B S Emanue

D A Driscoll

Division of Human

Genetics and

Molecular Biology,

Children's Hospital of

Philadelphia,

Philadelphia, PA, USA

D M McDonald-

McGinn

E H Zackai

B S Emanuel

D A Driscoll

Department of

Obstetrics and

Gynecology,

Gynecology,

University of

of Medicine, PA, USA

E H Zackai

D A Driscoll

Department of Plastic and Reconstructive Surgery, University of Pennsylvania School of Medicine, PA, USA

D M McDonald-

McGinn

E H Zackai

B S Emanuel

D A Driscoll

L A Whitaker

Correspondence to: Dr Lynch,

Department of Neurology,

Hospital of the University of

Pennsylvania,

3400 Spruce Street,

Philadelphia, PA 19104,

USA.

Received 12 December 1994 Revised version accepted for publication 23 February

1994

\begin{abstract}
Velocardiofacial syndrome and DiGeorge syndrome have not previously been associated with central nervous system degeneration. We report a 34 year old man who presented for neurological evaluation with cerebellar atrophy of unknown aetiology. On historical review, he had neonatal hypocalcaemia, an atrial septal defect, and a corrected cleft palate. His physical examination showed the characteristic facies of velocardiofacial syndrome as well as dysmetria and dysdiadochokinesia consistent with cerebellar degeneration. Molecular cytogenetic studies showed a deletion of 22q11.2. This man is the first reported patient with the association of a neurodegenerative disorder and 22q11.2 deletion syndrome.
\end{abstract}

( $\mathcal{H}$ Med Genet 1995;32:561-563)

Microscopic and submicroscopic deletions of chromosome 22q11.2 have been found in the majority of patients with DiGeorge syndrome (DGS) and velocardiofacial syndrome (VCFS). VCFS is characterised by cardiac defects, palatal anomalies, developmental delay, and a characteristic facies. ${ }^{1}$ This condition shares features with DGS such as neonatal hypocalcaemia and decreased lymphoid tissue. ${ }^{23}$ Cytogenetic analysis using high resolution banding techniques detects interstitial deletions of chromosome 22q11 in $25 \%$ of patients with DGS and in $20 \%$ of patients with VCFS. ${ }^{45}$ Molecular studies using DNA dosage analysis or fluorescence in situ hybridisation (FISH) detect microdeletions in $89 \%$ of patients with DGS and $80 \%$ of patients referred with the diagnosis of VCFS ${ }^{67}$

Neurological abnormalities apart from developmental delay and hypotonia have not been commonly reported in association with either syndrome. Some patients with VCFS develop psychiatric abnormalities resembling schizophrenia as they mature. Structural abnormalities, such as a small cerebellar vermis, a small posterior fossa, and cysts adjacent to the lateral ventricles, have been detected by brain magnetic resonance imaging scans. ${ }^{810}$ Here, we report a patient with VCFS and progressive central nervous system dysfunction involving primarily the cerebellum.

\section{Case report}

The patient was the term product of a normal pregnancy with a neonatal course complicated by hypocalcaemia and tetany. A cardiac murmur was noted at that time. He had delayed motor milestones at 11 months of age, and poorly articulated speech was noted at the age of 4 years. Cardiac catheterisation at 8 years of age showed an atrial septal defect. A submucous cleft palate, bifid uvula, and velopharyngeal incompetence were noted at 18 years upon presentation to our plastic surgeon for correction of a prominent nasal tip.

His motor and cognitive milestones were slightly delayed throughout development. $\mathrm{He}$ sat up at 11 months of age, walked at 17 months, and had a vocabulary of single words and phrases at 4 years. He attained the ability to ride a bicycle at 5 years. By formal evaluation at the age of 5 years, he was felt to be delayed by one year. Neuropsychological testing at 11 years indicated a verbal IQ of 82 and a performance IQ of 94 . Evaluation by a paediatric neurologist at the age of 11 years showed a mild left hemiparesis, and a left extensor plantar response without prominent coordination abnormalities. At 28 he had insidious onset of gait difficulty, stiffness of his muscles, tinnitus, and dysarthria. These problems progressed slowly over the next two years, and he lost the ability to ride a bicycle and to drive. At the age of 31 he was evaluated at our hospital. His general examination was remarkable for deep set eyes, a prominent nasal root with a bulbous, bifid tip, and small but prominent ears with thick, overfolded helices (fig 1). Dermatoglyphics were not discernible. His neurological examination showed a normal mental status with a paucity of facial expression. His speech was mildly dysarthric and hypophonic. Cranial nerves were normal. Muscle tone was increased symmetrically in both the arms and legs. His reflexes were symmetrically increased with pathological spread of the adductor and knee jerks. His left plantar response was extensor and his right plantar response was flexor. Finger to nose testing showed bilateral dysmetria which was worse on the left; rapid alternating movements were poorly performed bilaterally. Bradykinesia was noted in the initiation of finger tapping movements. His sensory examination was normal. His gait was wide based, and the legs were stiff.

The progressive neurological dysfunction suggested a degenerative disorder of the central nervous system. An MRI scan of his head 

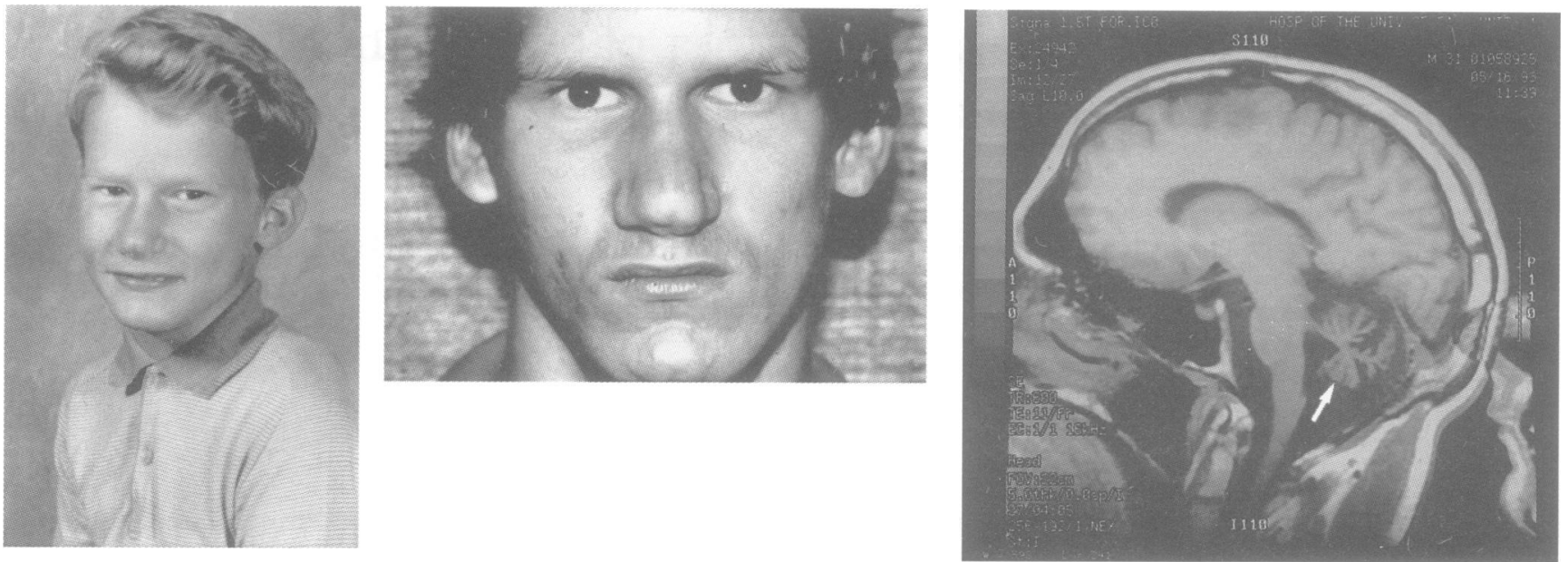

Figure 1 Photographs of the patient aged 10 (left) and 18 (right).

showed vermian and hemispheric cerebellar atrophy, calcification of the basal ganglia, a small brainstem without focal loss of volume, and multiple white matter lucencies on T2 weighted images (fig 2 ). The white matter lesions were suggestive of axonal loss, ischaemia, or demyelination. A serological test for syphilis was negative. Serum levels of $\mathbf{B}_{12}$, folate, calcium, heavy metals, ceruloplasmin, and thyroid function tests were normal.

The findings of cleft palate, developmental delay, atrial septal defect, neonatal hypocalcaemia, and dysmorphic facies suggested the diagnosis of VCFS. Cytogenetic analysis using high resolution banding techniques showed an interstitial deletion of chromosome 22q11.2 (del(22) (q11.21-q11.23)). FISH of metaphase chromosomes with cosmid probes specific to locus D22S75 (N25) within the DGS commonly deleted region in $22 \mathrm{q} 11.2$ and a control probe ( $\cos 82$ ), which maps to the distal long arm of chromosome 22, confirmed the presence of a deletion in the proband.

\section{Discussion}

Our patient presented with a progressive neurodegenerative disorder and the characteristic clinical manifestations of VCFS. The progressive nature of his difficulties was shown by the loss of specific motor and speech abilities. These were superimposed on a pattern of mild developmental delay seen commonly in VCFS. His neurological dysfunction most prominently involved the cerebellum with less involvement of the basal ganglia and pyramidal tracts. These findings agreed with his brain MRI scan, which indicated profound cerebellar change and lesser abnormalities in the remainder of his brain. The combination of radiological abnormalities, his progressive course, and the absence of toxic exposures confirms the diagnosis of an idiopathic cerebellar and multisystem (pyramidal, basal ganglia) degeneration.

That the VCFS and cerebellar atrophy are related in this patient is suggested by several factors. Both entities are rare disorders. The incidence of VCFS has been estimated at 1 per 10000 live births. ${ }^{1-3}$ Cerebellar atrophies probably represent many distinct disorders but
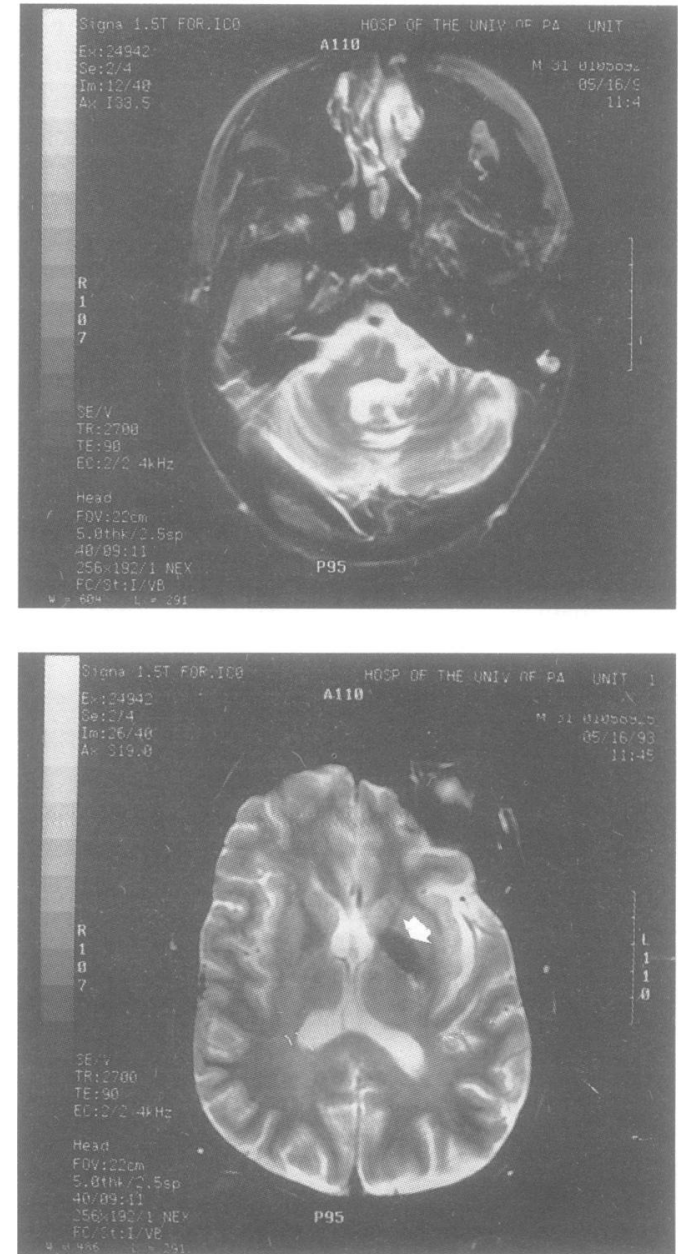

Figure 2 Brain MRI scan of the patient. Multiple central nervous system abnormalities were found, including decreased size of the cerebellar vermis and hemispheres (top, arrow, $T_{1}$ sagittal image). The brainstem was also decreased in size (middle, $T_{2}$ weighted image), and the basal ganglia were hypointense on $T_{2}$ weighted images (bottom, arrow), consistent with calcification. The asymmetry seen in the bottom scan results from the patient's position in the scanner.

the most common of these, Friedreich's ataxia, has an incidence of approximately 1 in 50000 people. ${ }^{11}$ Other structural abnormalities of the central nervous system, including three patients with holoprosencephaly, have been described in VCFS. ${ }^{12}$ Recently, brain MRI scans in a series of patients with VCFS showed structural brain anomalies in several patients including 
decreased size of the cerebellar vermis. ${ }^{10}$ High signal abnormalities in the white matter on T2 weighted imaging (as seen in our patient) were also observed. Although no neurological correlations were reported in these subjects, these abnormalities may become more clinically apparent as the population of patients with VCFS ages, as has been observed for the psychiatric manifestations of this disorder. ${ }^{8}$ These reports suggest that the cerebellar atrophy present in our patient by clinical and radiographic criteria is a manifestation of the underlying deletion syndrome.

This work was performed while DRL was a Pfizer postdoctoral fellow. The authors wish to thank Beatrice Sellinger for her technical assistance.

1 Shprintzen RJ, Goldberg R, Young D, Wolford L. The velocardiofacial syndrome: a clinical and genetic analysis. Pediatrics 1981;67:167-72.

2 Emanuel BS, Driscoll D, Goldmuntz E, et al. Molecular and phenotypic analysis of the chromosome 22 microdeletion syndromes. In: Epstein CJ, ed. Phenotypic mapping of Down syndrome and other aneuploid conditions. New York: Wiley Liss, 1993:207-24.

3 Kelly D, Goldberg R, Wilson D, et al. Confirmation that the velocardiofacial syndrome is associated with haploinsufficiency of genes at chromosome 22 . Am $7 \mathrm{Med}$ Genet 1993;45:308-12.

4 Driscoll DA, Spinner NB, Budarf ML, et al. Deletions and microdeletions of $22 \mathrm{q} 11.2$ in velocardiofacial syndrome. Am $\mathcal{F}$ Med Genet 1993;44:261-8.

5 Wilson DI, Cross IE, Goodship JA, et al. A prospective cytogenetic study of 36 cases of DiGeorge syndrome. $A m$ f Hum Genet 1992;51:957-63.

6 Driscoll DA, Salvin J, Sellinger B, et al. Prevalence of 22q11 microdeletions in DiGeorge and velocardiofacial syndromes: implications for genetic counselling and prenatal diagnosis. F Med Genet 1993;30:813-17.

7 Driscoll DA, Goldmuntz E, Emanuel BS. Detection of 22q11 deletions in patients with conotruncal cardiac malformations, DiGeorge, velocardiofacial and conotruncal anomaly face syndromes. Proceedings of the Fourth anomaly face syndromes. Proceedings of the Fourth International Symposium on Etiolog

8 Shprintzen RJ, Goldberg R, Golding-Kushner KJ, Marion RW. Late onset psychosis in the velocardiofacial syndrome. $\mathrm{RW}$. Late onset psychosis in the ve

9 Goldberg R, Motzkin B, Marion RW, Scambler PJ, Shprintzen RJ. Velocardiofacial syndrome: a review of 120 patients. Am F Med Genet 1993;45:313-19.

10 Mitnick RJ, Bello JA, Shprintzen RJ. Brain anomalies in velo-cardio-facial syndrome. Am $\mathscr{f}$ Med Genet 1994;54: $100-6$.

11 Harding AE. Hereditary ataxia and related disorders. In: Asbury AK, McKhann G, McDonald WI, eds. Disease of the nervous system: clinical neurobiology. Philadelphia: Saunders, 1992;1169-78.

12 Wraith JE, Super M, Watson GH, Phillips M. Velocardiofacial syndrome presenting as holoprosencephaly. Clin Genet 1985;27:408-10. 